\title{
Laugh Your Way to Persuasive Communication
} COMMUNICATION CORNER No. 34

\author{
by Philip Yaffe
}

\section{Editor's Introduction}

Each "Communication Corner" essay is self-contained; however, they build on each other. For best results, before reading this essay and doing the exercise, go to the first essay "How an Ugly Duckling Became a Swan," then read each succeeding essay.

Have you ever noticed that people who tell jokes well usually give good speeches? This is not a coincidence. Telling jokes and giving speeches have more in common than it might appear. We can benefit from these similarities. 


\title{
Laugh Your Way to Persuasive Communication
}

\author{
COMMUNICATION CORNER NO. 34
}

\author{
by Philip Yaffe
}

If you can tell a joke well, you already possess many of the skills you need to write a persuasive marketing plan, sales letter, financial report, new product proposal, etc. Equally, you already possess many of the skills you need to prepare persuasive speeches and other types of oral presentations.

Really? Just think about it. A well-constructed joke perfectly fulfills two critical criteria of persuasive communication: clarity and conciseness.

To better understand this, we first need to determine the true meanings of "clarity" and "conciseness." As detailed in "The Three Acid Tests of Persuasive Communication," this can best be done by giving them objective definitions, almost like a mathematical formula.

\section{Clarity}

To achieve clarity-to ensure that virtually everyone will understand what you are saying-you must do three things.

- Emphasize what is of key importance

- De-emphasize what is of secondary importance.

- Eliminate what is of no importance.

In symbols: $\mathbf{C l}=\mathbf{E D E}$

To apply the formula, whenever you write you must first decide what really is of key importance, i.e. what are the fundamental ideas you want your audience to take away from your text or discourse?

This is not always easy to do. It is far simpler to say that everything is of key importance, so you put in everything you have. But there is a dictum that warns: If everything is important, then nothing is. In other words, unless you first do the work of defining what you really want your audience to know, they won't do it for you. They will simply get lost in your words and either give up or come out the other end not knowing what it is you were trying to say. 
What about the second element of the formula, de-emphasize what is of secondary importance? You don't want key information and ideas to get lost in the details. If you clearly emphasize what is of key importance, then whatever is left over is automatically deemphasized.

Finally, you need to eliminate what is of no importance. Why? Because just as you don't want your key ideas to get lost in the details, you certainly don't want them to get lost in elements that have no business being there in the first place.

\section{Conciseness}

To achieve conciseness, your text or discourse must be as:

- Long as necessary

- Short as possible

In symbols: $\mathbf{C o}=\mathbf{L S}$

If you have fulfilled the criteria of "clarity" correctly, you already understand "as long as necessary." It means covering all the ideas of key importance you have identified, and all the ideas of secondary importance needed to support and/or elaborate these key ideas.

Note that nothing is said here about the number of words, because it is irrelevant. If it takes 500 words to be "as long as necessary," then 500 words must be used. If it takes 1,500 words, then this is all right too. The important point is that you actually say everything that really needs to be said.

Then what is meant by "as short as possible?" Once again, this has nothing do to with the number of words. It is useless to say at the beginning, "I must not use more than 300 words on this subject," because 500 words may be the minimum necessary.

"As short as possible" means staying as close as you can to the minimum. But not because people prefer short texts and presentations; in the abstract the terms "long" and "short" have no meaning. The important point is, all words beyond the minimum tend to reduce clarity.

We should not be rigid about this. If being "as long as necessary" can be done in 500 words and you use 520, this is probably a question of individual style; it does no harm. However, if you use 650 words, it is almost certain that the message will not be completely clear-and your audience will become bored, confused, or lost.

In sum, conciseness means saying what needs to be said in the minimum number of words. 
So how does all of this relate to jokes? If a text or oral presentation fails in its purpose, you often don't know it until a long time later. Feedback is not instantaneous. If you fail with a joke, you know it immediately.

To see how this works in practice, here are two versions of the same joke. Version No. 1 shows what it would look like by ignoring the formulas for clarity and conciseness. Version No. 2 shows what it would look like with the formulas properly applied.

But a word of warning, the first version may become rather tedious, so if you are inclined to fall asleep while reading it, jump directly to Version No. 2.

\section{Version No. 1}

Arthur is taking a trip from Dublin to New York. He gets on the plane at Dublin Airport and straps himself into his seat. The plane takes off. About an hour later, the intercom clicks on.

A voice is heard saying, "Ladies and gentlemen, this is your captain speaking. The weather across the Atlantic is clear and calm. But I have to report to you that there has been a malfunction in our No. 1 engine and for safety reasons I will have to shut it down. However, let me assure you that there is nothing to worry about. This is a superbly designed, superbly engineered aircraft and we can easily fly on three engines. But I will need to reduce our air speed and I estimate that we will be about 30 minutes late arriving in New York."

After about another hour's flying time, the sound of the intercom is heard again. Once again it is the captain saying, "Ladies and gentlemen, this is your captain speaking. The weather across the Atlantic is still clear and calm. However, I must report to you a malfunction in our No. 2 engine and for safety reasons I will have to shut it down. But once again let me assure you that there is nothing to worry about. This is a superbly designed, superbly engineered aircraft and we can easily fly on two engines. But once again I will have to reduce our air speed and I estimate that we will be about one-and-a-half hours late arriving in New York."

About an hour later, it happens again. The intercom clicks on and a voice is heard. "Ladies and gentlemen, this is your captain speaking. The weather across the Atlantic remains clear and calm. However, I must report to you that we now also have a malfunction in our No. 3 engine and for safety reasons I will have to shut it down. But again let me assure you that there is nothing to worry about. This is a superbly designed, superbly engineered aircraft and we can easily fly on one engine. But once again I will have to reduce our air speed and I now estimate that we will now be about three hours late arriving in New York."

At this point, Arthur lets out a groan. "Good grief, I hope the captain doesn't have to shut down the fourth engine. Otherwise, we could be up here all night!" 


\section{Version No. 2}

A plane takes off from Dublin heading to New York. After about an hour, the intercom clicks on and a voice is heard.

"Ladies and gentlemen, this is your captain speaking. I have to report that due to a malfunction we have lost the use of our No. 1 engine. But let me assure you that there is nothing to worry about. This is a superbly designed, superbly engineered aircraft. We can easily fly on three engines. However, I will have to reduce speed and I estimate we will be about 30 minutes late arriving in New York."

A bit later the intercom again clicks on.

"Ladies and gentlemen, this is your captain speaking. I have to report that we have now lost use of our No. 2 engine. But once again, let me assure you that there is nothing to worry about. This is a superbly designed, superbly engineered aircraft and we can easily fly on two engines. However, I will once again have to reduce speed and I now estimate that we will be about oneand-a-half hours late arriving in New York."

A bit more times goes by. Once again the intercom clicks on.

"Ladies and gentlemen, this is your captain speaking. I have to report that we have now also lost use of our No. 3 engine. But once again, let me assure you that there is nothing to worry about. This is a superbly designed, superbly engineered aircraft and we can easily fly on one engine. However, I will again have to reduce speed and I estimate we will now be about three hours late arriving in New York."

At this point, Arthur lets out a groan. "Good grief, I hope we don't lose use of the fourth engine. Otherwise, we could be up here all night!"

Version No.1 contains 406 words, while Version No. 2 contains only 298. And I think you will agree that the second version is much funnier. Why? Because it fully respects the formulas for clarity and conciseness, as all good jokes do.

Here are two more clear, concise stories. They are not jokes of the "ha-ha" variety, but I am certain they will put a smile on your face.

\section{All About Penguins}

A little girl goes into a library and asks the librarian, "Do you have any books about penguins?" The librarian goes to the shelves and gives the little girl four or five books, which she sits down to read. A few minutes later, she comes up to the librarian's desk and returns them. "What's the matter, honey?" the librarian asks. "Don't you like these books about penguins?" "Oh no," 
the little girl replies. "They're great books! They're wonderful books. But . . . well, they just tell me much more about penguins than I really want to know."

\section{Why Does It Rain?}

A little girl (not the same one) asks, "Daddy, why does it rain?" Her father takes her on his knee and explains:

"Well, it rains to give water so the grass can grow. And it rains to give water so the flowers can grow. And it rains to give water so the shrubs can grow. And it rains to give water so the trees can grow. Now do you understand why it rains?"

"Oh yes, Daddy," she replies. "But ... why does it rain on the sidewalk?"

\section{About the Author}

Philip Yaffe was born in Boston, Massachusetts, in 1942 and grew up in Los Angeles, where he graduated from the University of California with a degree in mathematics and physics. In his senior year, he was also editor-in-chief of the Daily Bruin, UCLA's daily student newspaper. He has more than 40 years of experience in journalism and international marketing communication. At various points in his career, he has been a teacher of journalism, a reporter/feature writer with The Wall Street Journal, an account executive with a major international press relations agency, European marketing communication director with two major international companies, and a founding partner of a specialized marketing communication agency in Brussels, Belgium, where he has lived since 1974. He is the author of more than 30 books, which can be found easily in Amazon Kindle.

DOI: $10.1145 / 3447891$ 